\title{
Comment on Goldstein: Retinal rivalry and Troxler's effect
}

BARRY KIRKWOOD, DEPARTMENT OF PSYCHOLOGY, UNIVERSITY OF OTAGO, Dunedin, New Zealand

It is suggested that Goldstein's data on Troxler's effect reflect the influence of eye-movement rather than the variables specified by the author. An alternative test of Goldstein's retinal interaction hypothesis is briefly outlined.

Goldstein (1967) investigated the proposition that Troxler's effect (TE), the fading of contour in peripheral vision when a central point is fixated, is due to retinal rivalry. Making the reasonable assumption that retinal rivalry cannot occur in Ss who have had one eye removed by surgery or accident, the author argued that if retinal rivalry is responsible for $T E$, then these monocular Ss will not experience the effect. Conversely, if no interactive process is involved, there will be no difference between the TE reported by monocular Ss and binocular Ss who have one eye temporarily occluded. Goldstein found that monocular Ss did in fact report TE, but less frequently than the controls which led him to suggest a partial interaction process occurring in the central nervous system at levels above the retina and optic nerve.

Although the concept of a postretinal locus for $T E$ is substantially in accord with the conclusions drawn from other studies of the fading of visual images, e.g., Fry \& Robertson (1935), Clarke \& Belcher (1962), Gerrits et al (1966), it seems likely that Goldstein's data can be largely accounted for by eye-movement, a variable unspecified by the author.

The role of eye-movement in maintaining contour perception, demonstrated by Guilford (1927), has been further verified by the now substantial body of work using stabilized retinal images, e.g., Riggs et al (1953). Ditchburn \& Fender (1955). The relevance of these findings to TE has been shown by Clarke \& Belcher (1962) who introduced an artificial saccadic movement to the test figure at the moment fading was reported. It was found that frequency of seeing was positively related to the magnitude of angular movement of the target, the $50 \%$ level being reached with an angular movement of $8 \mathrm{~min}$ of arc. It is therefore, reasonable to assume that reduced eye-movement is as necessary a condition for $\mathrm{TE}$ as it is for contour adaptation under other stimulus conditions.

It is probable that the reported difference in TE frequency between monocular and binocular Ss is largely explicable in terms of different patterns of visual search adopted by the two groups.
The monocular Ss having a reduced visual field and an absence of oculomotor feedback from the contralateral eye would be expected to scan their visual field more actively and therefore show reduced TE. Similarly, the reported failure of some visually and neurologically normal Ss to experience TE may be simply due to their failure to maintain accurate fixation.

A better test of the role of retinal rivalry in TE would be to compare the frequency of disappearance of peripheral contour using binocular Ss under two conditions: with the contralateral eye simply occluded or with the contralateral eye rendered functionless by pressure-blinding or by massive pre-adaptation to bright light. Preliminary tests at this laboratory using these procedures show no significant difference in TE between conditions, indicating that the retinal interaction hypothesis is probably invalid.

The eye-movement hypothesis can also account for the differences in TE with Goldstein's stimulus figure in different angular orientations (see Figs. 1, 2, Goldstein, 1967). As eye-movements are predominantly in the horizontal plane it would be predicted that well-defined vertical contours would fade less readily than horizontal contours. As the distal portion of the stimulus figure used was T-shaped, one would predict that TE would be most frequent with the major axis of the figure at angular orientations of $45 \mathrm{deg}, 135 \mathrm{deg}, 225 \mathrm{deg}$ and $315 \mathrm{deg}$, as Goldstein's data in fact show.

\section{REFERENCES}

CLARKE, F. J. J., \& BELCHER, S. J. On the localization of Troxler's effect in the visual pathway. Vis. Res., 1962, 2, 53-68.

DITCHBURN, R. W., \& FENDER, D. H. The stabilized retinal image. Optica Acta, 1955, 2, 128-133.

FRY, G. A., \& ROBERTSON, V. M. The physiological basis of the periodic merging of area into background. Amer. J. Psychol., 1935, 45, 644-655.

GERRITS, H. J. M., DE HAAN, B., \& VENDRIK, A. J. H. Experiments with retinal stabilized images. Relations between observations and neural data. Vis. Res., 1966, 6, 427-440.

GOLDSTEIN, A. G. Retinal rivalry and Troxler's effect. Psychon. Sci., 1967, $7,427-428$

GUILFORD, J. P. Fluctuations of attention with weak visual stimuli. Amer. J. Psychol., 1927, 38, 534-535.

RIGGS, L. A., RATLIFF, F., CORNSWEET, J. C., \& CORNSWEET, T. N. The disappearance of steadily fixated test objects. J. Opt. Soc. Amer., $1953,53,110-120$.

\section{Reply to Kirkwood}

ALVIN G. GOLDSTEIN, DEPARTMENT OF PSYCHOLOGY, UNIVERSITY OF MIISSOURI, Columbia, Mo. 65201

Kirkwood's (1968) comment points to a possible reason for the reduced occurrence of TE in one-eyed Ss. He correctly assumed that I did not collect eye movement data from my Ss. Obviously, this is an empirical question which can be answered by a suitable study of normal and one-cyed Ss. Until that study is performed-or until relevant data from another source can be found $\cdot I$ find it difficult to accept Kirkwood's interpretation because it offers no help in understanding the rather unusual distribution of TE which is evident in Fig. 1 of my earlier paper $(1967)$. Specifically, almost no TE was clicited from the $180 \mathrm{deg}$, $225 \mathrm{deg}, 270 \mathrm{deg}$, and $315 \mathrm{deg}$ spatial meridians, whereas TI in the remaining meridians was much reduced (compared to normals) but still present. This inbalance was as striking as the overall reduction of 'lt:
With regard to the difference in TE as a function of stimulus orientation, Kirkwood's explanation is almost certainly incorrect on two counts. As I mentioned in my earlier report (Goldstein, 1967), Craig and Lichtenstein (1953) found the wave-like pattern of response when they measured TE along numerous retinal meridians. Their stimulus lacked the "T-shaped" terminal point Kirkwood implicates in his comment. Furthermore, as far as I can tell, the location of the fading contour is not related to the orientation of the line.

\section{REFERENCES}

CRAll;, I: A., \& LICHTINSTEIN, M. Visibility-invisibility cycles as a function of stimulus urientation. Amer. J. Psychol., 1953, 66, 554-563.

(i)LDSTLIN. A. G. Retinal rivalry and Troxler's effect. Psychon. Sci., 1967, $7,427-42 \%$.

KIRKWOOD, B. Comment on Goldstein: Retinal rivalry and Troxler's effect. Psychon. Sci. 1968, 11, 54 